\title{
Maternal and Perinatal Outcomes of Pregnant Women with Heart Disease in Three Yaoundé Referral Hospitals
}

\author{
Jean Dupont Kemfang Ngowa ${ }^{*}{ }^{\mathbb{D}}$, Calixte Galilée Fotsing Kengne ${ }^{1}$, Christiane Nsahlai ${ }^{1}$, \\ Boombhi Jérôme², Felix Essiben', Wilfried Loic Tatsipie ${ }^{1}$, Jovanny Tsuala Fouogue ${ }^{3}$, \\ Pascal Foumane ${ }^{1}$
}

\begin{abstract}
${ }^{1}$ Department of Obstetrics and Gynaecology, Faculty of Medicine and Biomedical Sciences of the University of Yaounde 1, Yaoundé, Cameroon

${ }^{2}$ Department of Internal Medicine/Cardiology, Faculty of Medicine and Biomedical Sciences of the University of Yaounde 1, Yaoundé, Cameroon

${ }^{3}$ Department of Obstetrics, Gynaecology and Maternal Health, Faculty of Medicine and Pharmaceutical Sciences of the University of Dschang, Dschang, Cameroon

Email: *jdkemfang@yahoo.fr
\end{abstract}

How to cite this paper: Ngowa, J.D.K., Kengne, C.G.F., Nsahlai, C., Jérôme, B., Essiben, F., Tatsipie, W.L., Fouogue, J.T. and Foumane, P. (2022) Maternal and Perinatal Outcomes of Pregnant Women with Heart Disease in Three Yaoundé Referral Hospitals. Open Journal of Obstetrics and Gynecology, 12, 93-103. https://doi.org/10.4236/ojog.2022.121009

Received: December 2, 2021

Accepted: January 24, 2022

Published: January 27, 2022

Copyright (อ 2022 by author(s) and Scientific Research Publishing Inc. This work is licensed under the Creative Commons Attribution International License (CC BY 4.0).

http://creativecommons.org/licenses/by/4.0/ (c) (i) Open Access

\begin{abstract}
Heart disease in pregnancy is the cause of significant maternal and perinatal morbidity. We wanted to evaluate the maternal and perinatal outcomes of pregnant women with heart disease in Yaoundé, Cameroon. This was a cross sectional study with retrospective data collection of 45 pregnancies in 42 women with heart disease followed at three Yaoundé referral hospitals in Yaoundé, Cameroon from January $1^{\text {st }} 2015$ to December $31^{\text {st }} 2020$. We collected data on maternal obstetrical and perinatal outcomes. The frequency of pregnancies with heart diseases was $0.1 \%$. The mean maternal age was 29.05 \pm 6.5 years. At first antenatal visit, all patients were in class I (84.4\%) and II (15.6\%) of the New-York Heart Association (NYHA) functional class. Valvular heart disease (51.1\%) was the most common type followed by cardiomyopathy (37.7\%). Over half of the deliveries were vaginal (51.1\%). A cesarean section was generally indicated for the usual obstetrical reasons $(54.5 \%)$ and for heart disease (31.8\%). Complications included 17 (37.7\%) cases of heart failure, $6(13.3 \%)$ cases of pulmonary edema, $2(04.4 \%)$ cases of pulmonary embolism, 3 (06.6\%) maternal deaths and $3(06.3 \%)$ perinatal deaths, $14(29.7 \%)$ premature births and 3 cases of (6.3\%) intrauterine growth retardation. The maternal deaths were cases complicated by pulmonary edema and all had dilated cardiomyopathy. The maternal and perinatal outcomes of pregnant women with heart disease are marked in our environment by increased morbidity and mortality. Therefore, it is necessary to improve the prenatal, per partum and postpartum management of this high-risk group.
\end{abstract}




\section{Keywords}

Heart Disease, Pregnancy, Perinatal, Delivery, Cesarean Section

\section{Introduction}

Heart disease involves a broad spectrum of pathologies which might be congenital or acquired, functional or structural, cyanotic or acyanotic, or may include endocardial, myocardial or pericardial defects [1].

Cardiac diseases in pregnancy are rare. In the 1930s, it was estimated that $1 \%$ to $2 \%$ of all pregnancies were complicated by maternal cardiac disease and that $6 \%$ of these women died during pregnancy [2]. Current estimates of heart disease in pregnancy report a prevalence of $4 \%$ in the United States of America and worldwide estimates of $0.1 \%$ to $1.4 \%$ [3] [4]. Congenital heart disease is reported to be the most common cause of cardiac disease in pregnant women in developed countries [5]. A major reason for this increase is that recent advances in medical and surgical treatment have improved long-term outcomes of children with congenital heart disease and consequently, more women with congenital heart disease are reaching childbearing age and conceiving [5]. Sub-Saharan Africa is characterized by a high prevalence of rheumatic fever and rheumatic valvular heart disease (VHD). Prevalence of rheumatic heart disease has been estimated at two to three cases per 1000 among school-age children in Africa who underwent clinical screening, and was recently reported to be about 10 fold higher if they also had an ultrasound examination [6] [7].

Pregnancy leads to increased cardiac output, as a result of increased heart rate and stroke volume, increased circulating blood volume and decreased peripheral vascular resistance. At the time of delivery, uterine contraction and maternal effort further increase cardiac output. These hemodynamic changes might result in adverse maternal and fetal outcomes [8]. Cardiovascular modifications during pregnancy can worsen cardiac disease compromising maternal vital prognosis during labor and delivery and even in the postpartum period. Previous studies performed in industrialized countries have shown that pregnancy in women with heart disease is associated with significant cardiac and neonatal complications, despite optimum obstetrical and cardiac care [6]. The management of pregnant women with heart disease in developing countries is a medical challenge due to financial constraints, inadequate hospital equipment, cultural and social barriers.

In Cameroon, no formal study has been done on the subject. We thus set out to evaluate maternal and perinatal outcomes of 45 pregnant women with heart disease in three Yaoundé referral hospitals.

\section{Materials and Methods}

This study was a cross sectional study with retrospective evaluation of mater- 
no-fetal outcome of pregnancies with heart disease followed at three Yaoundé referral hospitals including: the Yaoundé Central Hospital, the Gyneco-obstetrics and Pediatrics Yaoundé Hospital and the Essos Hospital Center, from January $1^{\text {st }}$ 2015 to December $31^{\text {st }} 2020$. We included pregnant patient files with pre-existent or newly diagnosed heart disease during pregnancy approved by a cardiologist based on clinical and paraclinical (echocardiography and electrocardiogram (ECG) anomaly) evidence of heart disease. We excluded pregnant patients' files which were unusable. Ethical clearance was obtained from the institutional review board of the Faculty of Medicine and Biomedical Sciences of the University of Yaoundé I and research authorization obtained from the directorate of the above-mentioned hospitals. Thereafter, we collected data from patients' files during pregnancy, delivery, postpartum and from birth registers.

In the present study, each pregnancy was considered an independent event in case the patient had been pregnant on different occasions during our study period. Variables were recorded from the antepartum, peripartum and post-partum periods. These included: maternal age, parity, gravidity, monthly revenue, New York Heart Association (NYHA) functional class, cardiac intervention prior to pregnancy, cardiac medication, cardiac lesion type, echocardiographic and electrocardiogram lesion details, the delivery mode and materno-fetal outcome. Maternal outcome was assessed based on complications during pregnancy, labor, postpartum or maternal death. Perinatal outcome (preterm birth, birth weight, Apgar score, intrauterine growth retardation (IUGR), neonatal respiratory distress, still birth and neonatal death) was noted in each case.

Data collected were entered in CSPro 7.3 and analysed with SPSS 23.0. Data were presented as frequencies, proportions and mean \pm S.D. Statistical significance was considered at the $95 \%$ confidence level $(p<0.05)$. The $\mathrm{x}^{2}$-test was applied for the association between certain variables and materno-fetal outcome.

\section{Results}

We recorded 45 cases of pregnant women with heart disease from 45,546 deliveries giving a frequency of $0.1 \%$ heart disease during pregnancy. Table 1 shows the basic maternal characteristics. The mean maternal age was $29.05 \pm 6.5$ years with a modal age class of 30 - 35 years and ages ranging between 18 and 44 years. A little more than half of patients (53.3\%) earned less than 100 USD per month with a few of them having a health insurance coverage (only $11.1 \%$ of pregnancies were covered by health insurance). Heart disease was diagnosed before pregnancy in $55.6 \%$ of cases. At first antenatal visit, all patients were in class I or II of the NYHA functional class.

Table 2 shows heart disease distribution. Valvular heart disease (51.1\%) was the most common type of heart disease followed by cardiomyopathy (37.7\%). Mitral insufficiency (33.3\%) was the most common valvular lesion while dilated cardiomyopathy (24.4) was the most common cardiomyopathy type. We had one case of ventricular tachychardia and one case of ventricular extra-systoles. 


\subsection{Mode of Delivery}

Table 3 shows the different modes of delivery and indications of cesarean section. About half of deliveries were by the vaginal route and none of these were instrumental. Most of the cesarean sections were done for the usual obstetrical reasons. In $31.8 \%$ cardiac disease was the only indication for a cesarean delivery. Labor induction was done in $12.9 \%$ of cases.

Table 1. Basic maternal characteristics.

\begin{tabular}{|c|c|c|}
\hline Maternal characteristics & Number; $\mathrm{N}=45$ & $\%$ \\
\hline \multicolumn{3}{|c|}{ Age (years) } \\
\hline$[15-25[$ & 14 & 31.1 \\
\hline$[25-35[$ & 23 & 51.1 \\
\hline$[35-45[$ & 8 & 17.8 \\
\hline \multicolumn{3}{|c|}{ Estimated monthly revenue of patients (USD) } \\
\hline$<100$ & 24 & 53.3 \\
\hline $100-300$ & 15 & 33.3 \\
\hline $300-500$ & 6 & 13.4 \\
\hline \multicolumn{3}{|c|}{ Health insurance coverage during pregnancy } \\
\hline No & 40 & 88.9 \\
\hline Yes & 5 & 11.1 \\
\hline \multicolumn{3}{|c|}{ Obstetrical history } \\
\hline Primigravida & 18 & 40 \\
\hline Multigravida & 27 & 60 \\
\hline \multicolumn{3}{|c|}{ Time of heart disease discovery with respect to current pregnancy } \\
\hline Before pregnancy & 25 & 55.6 \\
\hline During pregnancy & 9 & 20 \\
\hline Postpartum & 11 & 24.4 \\
\hline \multicolumn{3}{|c|}{ NYHA functional class at first ANC } \\
\hline I & 38 & 84.4 \\
\hline II & 7 & 15.6 \\
\hline III & 0 & 0 \\
\hline IV & 0 & 0 \\
\hline \multicolumn{3}{|c|}{ Heart diseases treatment before pregnancy } \\
\hline Surgical treatment & 1 & 2.2 \\
\hline Medications & 5 & 11.1 \\
\hline No treatment & 39 & 86.7 \\
\hline
\end{tabular}

NYHA: New York Heart Association functional class; ANC: antenatal care. 
Table 2. Distribution of study population according to heart disease type 2 .

\begin{tabular}{|c|c|c|}
\hline Heart disease type & Number; $N=45$ & $\%$ \\
\hline Valvular heart disease & 23 & 51.1 \\
\hline -Mitral stenosis & 5 & 11.1 \\
\hline -Mitral insufficiency & 15 & 33.3 \\
\hline -Aortic stenosis & 1 & 02.2 \\
\hline -Aortic insufficiency & 2 & 04.4 \\
\hline Congenital heart disease & 6 & 13.3 \\
\hline Ventricular septal defect & 5 & 11.1 \\
\hline Patent ductus arteriosus & 1 & 02.2 \\
\hline Cardiomyopathy & 17 & 37.7 \\
\hline Dilated & 11 & 24.4 \\
\hline Hypertrophic & 1 & 02.2 \\
\hline Peripartum & 5 & 11.1 \\
\hline Arrhythmia & 2 & 04.4 \\
\hline -Ventricular tachycardia & 1 & 02.2 \\
\hline -Ventricular extrasystoles & 1 & 02.2 \\
\hline Ischemic heart disease & 2 & 04.4 \\
\hline Association of heart disease type & 5 & 11.1 \\
\hline VHD + IHD & 1 & 02.2 \\
\hline $\mathrm{VHD}+\mathrm{CM}$ & 3 & 06.6 \\
\hline $\mathrm{CM}+$ arrythmia & 1 & 02.2 \\
\hline
\end{tabular}

CM: cardiomyopathy; VHD: valvular heart disease.

Table 3. Mode of delivery and Cesarean section indications.

\begin{tabular}{ccc}
\hline Variable & Number; $\mathbf{N}=\mathbf{4 5}$ & $\%$ \\
\hline Mode of delivery & & \\
\hline Vaginal & 23 & 51.1 \\
cesarean & 22 & 48.9 \\
\hline Indication of C/S; $\mathbf{n}=\mathbf{2 2}$ & & \\
\hline Obstetrical & 12 & $\mathbf{5 4 . 5}$ \\
Pre-eclampsia/eclampsia & 3 & 13.6 \\
Fetal distress & 4 & 18.2 \\
Cephalopelvic disproportion & 3 & 13.6 \\
Others & 2 & 9.1 \\
Cardiac disease & 7 & $\mathbf{3 1 . 8}$ \\
Obstetrical + cardiac disease & 3 & 13.7 \\
\hline Type of labor; $\mathbf{n}=\mathbf{3 1}$ & & 87.1 \\
\hline Spontaneous & 27 & 12.9 \\
\hline Induction & 4 & 75 \\
\hline Pharmacologic + mechanical (foley catheter) & 1 & 25 \\
\hline Induction method of labor; $\mathbf{n}=\mathbf{4}$ & 3 & \\
\hline Pharmacologic (misoprostol) & & \\
\hline
\end{tabular}

C/S: cesarean/section. 


\subsection{Maternal Outcome}

Table 4 shows the maternal outcomes of pregnancies with heart diseases in our study. We recorded 17 heart failures cases, 6 pulmonary edema cases and 2 thrombo-embolic events. As concerns obstetrical complications, pre-eclampsia was most common followed by post-partum hemorrhage. Also, we noted 3 maternal deaths $(06.6 \%)$. All three women died in a context of pulmonary edema and all had a dilated cardiomyopathy.

\subsection{Perinatal Outcome}

Perinatal outcome is summarized in Table 5. The mean gestational age (SD) at delivery was 35.77 weeks \pm 5 with maximum and minimum of 21 and 41 weeks, respectively. The mean birth weight was $2780.36 \pm 647 \mathrm{~g}$. Most newborns (76.5\%) weighed $>2.5 \mathrm{~kg}$. Furthermore, we recorded 14 preterm deliveries (29.7\%), 3 IUGR (06.3\%), 3 newborns had RDS (06.3\%) at delivery and 3 perinatal deaths (06.3\%) occurred. One congenital anomaly (laparoschisis) case was recorded. Ten percent of newborns had an Apgar score less than 7 requiring neonatal intensive care unit admission.

\subsection{Factors Associated to Materno-Fetal Outcome}

There is an association between heart disease type and the occurrence of preterm delivery, and between maternal death and heart disease type (Table 6).

Concerning the association between materno-fetal outcome and NYHA functional class, there is no significant association between these two variables. Preterm delivery is more frequent in NYHA II than NYHA I but this difference is not statistically significant (Table 7).

Table 4. Maternal outcome, $\mathrm{N}=45$.

\begin{tabular}{|c|c|c|c|c|}
\hline Variable & $\begin{array}{c}\text { During } \\
\text { pregnancy } \\
\text { n (\%) }\end{array}$ & $\begin{array}{l}\text { During } \\
\text { delivery; } \\
\text { n (\%) }\end{array}$ & $\begin{array}{c}\text { Postpartum; } \\
\text { n (\%) }\end{array}$ & $\begin{array}{c}\text { All } \\
\text { cases }\end{array}$ \\
\hline \multicolumn{5}{|c|}{ Medical complications } \\
\hline Heart failure & $7(15.6)$ & $5(11.1)$ & $5(11.1)$ & $17(37.7)$ \\
\hline Pulmonary edema & $1(02.2)$ & $1(02.2)$ & $4(08.8)$ & $6(13.3)$ \\
\hline Thrombo-embolic event & $0(0)$ & $2(4.4)$ & $0(0)$ & $2(04.4)$ \\
\hline Heart failure + Pulmonary edema & $1(2.2)$ & $0(0)$ & $0(0)$ & $1(02.2)$ \\
\hline None & $36(80)$ & $37(82.2)$ & $36(80)$ & NA \\
\hline \multicolumn{5}{|c|}{ Obstetrical complications } \\
\hline Pre-eclampsia & $6(13.3)$ & & $11(24.4)$ & $17(37.7)$ \\
\hline Eclampsia & 0 & & $1(02.2)$ & $1(02.2)$ \\
\hline Postpartum hemorrhage & 0 & & $4(08.8)$ & $4(08.8)$ \\
\hline Wound Infection & 0 & & $1(02.2)$ & $1(02.2)$ \\
\hline Others & $6(13.3)$ & & $0(0)$ & $6(13.3)$ \\
\hline Maternal death & & $3(06.6)$ & & $3(06.6)$ \\
\hline None & $27(60)$ & & $28(62.2)$ & NA \\
\hline
\end{tabular}


Table 5. Perinatal outcome.

\begin{tabular}{|c|c|c|}
\hline Perinatal outcome & Number; $N=47$ & $\%$ \\
\hline \multicolumn{3}{|l|}{ Total newborns } \\
\hline Live born & 44 & 93.6 \\
\hline Perinatal death & 3 & 06.3 \\
\hline \multicolumn{3}{|l|}{ Birth weight } \\
\hline Birth weight $<2500 \mathrm{~g}$ & 11 & 23.4 \\
\hline Birth weight $>2500 \mathrm{~g}$ & 36 & 76.5 \\
\hline \multicolumn{3}{|l|}{ Period of delivery } \\
\hline Preterm & 14 & 29.7 \\
\hline Term & 30 & 63.8 \\
\hline Post term & 1 & 02.1 \\
\hline \multicolumn{3}{|l|}{ Fetal complications } \\
\hline IUGR & 3 & 06.3 \\
\hline RDS & 3 & 06.3 \\
\hline Congenital anomaly & 1 & 02.1 \\
\hline None & 38 & 80.8 \\
\hline \multicolumn{3}{|l|}{ Apgar score $5^{\text {th }} \mathrm{min}$} \\
\hline$<7$ & 5 & 10.6 \\
\hline$\geq 7$ & 42 & 89.3 \\
\hline
\end{tabular}

IUGR: intra uterine growth retardation; RDS: respiratory distress syndrome.

Table 6. Association between heart disease type and materno-fetal outcome.

\begin{tabular}{ccccccc}
\hline Variable & VHD & CHD & CM & IHD & Arrhythmia & P value \\
& $\mathbf{n}(\%)$ & $\mathbf{n}(\%)$ & $\mathbf{n}(\%)$ & $\mathbf{n}(\%)$ & $\mathbf{n}(\%)$ & \\
\hline Maternal outcome & & & & & & \\
\hline Heart failure & $5(21.7)$ & $0(0)$ & $9(52.9)$ & $0(0)$ & $0(0)$ & 0.228 \\
Pulmonary edema & $3(13)$ & $0(0)$ & $3(17.6)$ & $0(0)$ & $0(0)$ & 0.437 \\
Thrombo-embolic event & $0(0)$ & $0(0)$ & $1(5.6)$ & $0(0)$ & $1(50)$ & 0.335 \\
Maternal death & $0(0)$ & $0(0)$ & $3(17.6)$ & $0(0)$ & $0(0)$ & $\mathbf{0 . 0 4 8}$ \\
\hline Perinatal outcome & & & & & & \\
\hline Preterm & $8(47.1)$ & $2(33.3)$ & $4(23.5)$ & $0(0)$ & $0(0)$ & $\mathbf{0 . 0 4 5}$ \\
Perinatal deaths & $2(11.7)$ & $0(0)$ & $1(5.8)$ & $0(0)$ & $0(0)$ & - \\
IUGR & $3(17.6)$ & $0(0)$ & $0(0)$ & $0(0)$ & $0(0)$ & - \\
$\quad$ RDS & $2(11.7)$ & $1(16.6)$ & $0(0)$ & $0(0)$ & $0(0)$ & 0.56 \\
Congenital anomaly & $1(16.7)$ & $0(0)$ & $0(0)$ & $0(0)$ & $0(0)$ & -
\end{tabular}

IUGR: Intra Uterine Growth Retardation; RDS: Respiratory Distress Syndrome, CHD: Congenital Heart Disease; CM: cardiomyopathy; VHD: valvular heart disease; $I H D$ : Ischemic Heart Disease. 
Table 7. Association between materno-fetal outcome and NYHA functional class.

\begin{tabular}{cccccc}
\hline Variable & $\begin{array}{c}\text { NYHA I } \\
\mathbf{n}(\%)\end{array}$ & $\begin{array}{c}\text { NYHA II } \\
\mathbf{n}(\%)\end{array}$ & $\begin{array}{c}\text { NYHAIII } \\
\mathbf{n}(\%)\end{array}$ & $\begin{array}{c}\text { NYHAIV } \\
\mathbf{n}(\%)\end{array}$ & P-value \\
\hline Maternal outcome & & & & & \\
\hline Heart failure & $10(26.3)$ & $2(28.6)$ & $0(0)$ & $0(0)$ & 0.904 \\
Pulmonary edema & $4(10.5)$ & $1(14.3)$ & $0(0)$ & $0(0)$ & 0.771 \\
Thrombo-embolic event & $2(5.3)$ & $0(0)$ & $0(0)$ & $0(0)$ & 0.535 \\
Maternal death & $2(5.3)$ & $1(14.3)$ & $0(0)$ & $0(0)$ & 0.379 \\
\hline Perinatal outcome & & & & & \\
\hline Preterm & $9(23.6)$ & $5(71.42)$ & $0(0)$ & $0(0)$ & 0.06 \\
Perinatal deaths & $3(8.1)$ & $1(14.3)$ & $0(0)$ & $0(0)$ & 0.21 \\
IUGR & $3(8.1)$ & $0(0)$ & $0(0)$ & $0(0)$ & - \\
RDS & $3(8.1)$ & $0(0)$ & $0(0)$ & $0(0)$ & - \\
Congenital anomaly & $1(2.6)$ & $0(0)$ & $0(0)$ & $0(0)$ & - \\
\hline
\end{tabular}

\section{Discussion}

In the present study we found that the materno-fetal outcome of pregnancies with disease was generally poor in our setting. Our study population showed a frequency $0.1 \%$ of heart disease in pregnancy. This result is close to those found by Khemiri et al. in Tunisia (0.285\%) and Lima et al. in the U.S (0.2\%). Meanwhile, other authors such as Diao et al. in Senegal report a $2.7 \%$ rate of heart disease rate in pregnancy [5] [6] [9] [10] [11]. This high rate could be explained by the difference in the study populations; Diao et al. carried out their study in a specialized cardiology unit and reported the frequency with respect to this population group, compared to ours which was carried in an obstetrics unit and the frequency calculated with respect to the number of deliveries.

The mean age in our study population was $29.05 \pm 6.5$ years. This young age corresponds to data found in literature where the mean age at first birth in Cameroon is 20.1 years [12].

The financial accessibility to health care is a major problem in the African milieu. Social health care insurance is absent and thus patients are responsible for all healthcare related expenses. In the present study, only a few pregnancies were covered by health insurance and most patients had an estimated monthly revenue less than 100 USD. This goes along the same line with limited access to healthcare services in African settings due to multiple reasons including that of low socio-economic level [6].

Valvular lesions are usually the consequence of poorly treated rheumatic fever. Valvular heart disease (46\%) was the most common heart disease type found which is similar to those found in other African countries and different from those in developed countries where CHD were most frequent [3] [13] [14] [15]. In contrast to developed countries, the high rate of valvular heart disease could be explained by the higher rate of rheumatic fever in the African setting as a re- 
sult of low primary prevention during procedures and poor management of patients with rheumatic fever which could lead to heart lesions.

Delivery is a critical period of the occurrence of cardiac complications in pregnant women with heart disease. Scientific organizations recommend vaginal delivery, with shortening of the expulsion period, be the mode of delivery of choice in this group of women [14] [16] [17]. In this study, cesarean delivery represented $48.9 \%$ of cases, with non-obstetrical indications representing $31.8 \%$ thereof, and vaginal delivery $51.1 \%$, none of which was instrumental. Our cesarean rate is slightly greater than those reported by other authors such as Diao et al. in Senegal, Subbaiah et al. in India, Bonnet et al. in France having 37\%, 30\%, $37 \%$ cesarean section rates, respectively [5] [6] [18]. The high cesarean rate in our study could be explained by the high rate of non-obstetrical indications and also due to a lack of multidisciplinary management of patients during delivery (absence of a cardiologist). This situation results in more indications of cesarean section by the obstetrician because of the heart disease and its complications.

Previous studies in industrialized countries have shown that the increased risk associated with pregnancy in women with heart disease depends on the underlying cardiac condition, and the presence of risk factors, such as, older age, tobacco smoking, multiple gestations, anticoagulant therapy, poor functional class, cyanosis and left heart obstruction [19] [20] [21] [22] [23]. Maternal and fetal death are the worst outcomes we can get during pregnancy which should be avoided by preventive and curative measures. In the present study we noted 3 maternal deaths which were all secondary to pulmonary edema and these women all had a dilated cardiomyopathy. Also, we registered 3 perinatal deaths and a late abortion case in our study. These results challenge us to improve patient care and follow-up in our environment. There should be a multidisciplinary follow-up of these patients during labor including an obstetrician, neonatologist, cardiologist, anesthesiologist and improvement of technical facilities (provision for oxygen availability and resuscitation equipment in the different rooms).

We observed a significant association between heart disease types and prematurity, and between maternal death and heart disease types. Our results are similar to those reported by several authors in the literature [5] [14]. Our study had several limitations. It was a retrospective cohort study using administrative data. Data on maternal-fetal outcome were not always complete. However, the present study provided data on maternal-fetal outcome of pregnancies complicated by heart disease in our setting.

\section{Conclusion}

There are adverse materno-fetal outcomes of pregnant women with heart disease in our setting as seen by the high maternal and neonatal mortality rate. Valvular lesions are the most common heart disease type in pregnant women in our setting. Dilated cardiomyopathy is the most frequent heart disease type associated with maternal death. The Cesarean rate is high amongst these pregnant women 
with heart disease in our setting in contrast to the different scientific society recommendations. There is a great need to set up a multidisciplinary management of pregnant patients with heart disease in our setting to improve the outcome of these pregnancies. There is also a need to improve the infrastructure in our different referral hospitals for better management of these pregnancies with high risk of materno-fetal complications.

\section{Conflicts of Interest}

The authors declare no conflicts of interest regarding the publication of this paper.

\section{References}

[1] Millington, S., Arstall, M., Dekker, G., Magarey, J. and Clark, R. (2020) Adherence to Clinical Practice Guidelines for South Australian Pregnant Women with Cardiac Conditions between 2003 and 2013. PLOS ONE, 15, e0230459. https://doi.org/10.1371/journal.pone.0230459

[2] Klein, L.L. and Galan, H.L. (2004) Cardiac Disease in Pregnancy. Obstetrics and Gynecology Clinics of North America, 31, 429-459. https://doi.org/10.1016/j.ogc.2004.03.001

[3] Martin, S. and Arafeh, J. (2018) Cardiac Disease in Pregnancy. AACN Advanced Critical Care, 29, 295-302. https://doi.org/10.4037/aacnacc2018615

[4] Faivre, J., Verroust, N., Ghiglione, S. and Mignon, A. (2009) Cardiopathies et grossesse. Réanimation, 18, 215-222. https://doi.org/10.1016/j.reaurg.2009.02.002

[5] Subbaiah, M., Sharma, V., Kumar, S., Rajeshwari, S., Kothari, S.S., Roy, K.K., et al. (2013) Heart Disease in Pregnancy: Cardiac and Obstetric Outcomes. Archives of Gynecology and Obstetrics, 288, 23-27. https://doi.org/10.1007/s00404-013-2730-2

[6] Diao, M., Kane, A., Ndiaye, M.B., Mbaye, A., Bodian, M., Dia, M.M., et al. (2011) Pregnancy in Women with Heart Disease in Sub-Saharan Africa. Archives of Cardiovascular Diseases, 104, 370-374. https://doi.org/10.1016/j.acvd.2011.04.001

[7] Kimbally-Kaky, G., Gombet, T., Voumbo, Y., Ikama-Méo, S., Elenga-Mbola, B., Mbika-Cardorelle, A., et al. (2008) Rheumatic Heart Disease in Schoolchildren in Brazzaville. Médecine Tropicale: Revue du Corps de Santé Colonial, 68, 603-605.

[8] Isogai, T., Matsui, H., Tanaka, H., Kohyama, A., Fushimi, K. and Yasunaga, H. (2018) Clinical Features and Peripartum Outcomes in Pregnant Women with Cardiac Disease: A Nationwide Retrospective Cohort Study in Japan. Heart Vessels, 33, 918-930. https://doi.org/10.1007/s00380-018-1137-1

[9] Hu, J., Ye, Y., Lu, A., Chen, L., Mai, Y., Huang, G., et al. (2020) Pregnancy Outcomes in Patients with Heart Disease in China. American Journal of Cardiology, 125, 1718-1724. https://doi.org/10.1016/j.amjcard.2020.02.043

[10] Lima, F.V., Yang, J., Xu, J. and Stergiopoulos, K. (2017) National Trends and In-Hospital Outcomes in Pregnant Women with Heart Disease in the United States. American Journal of Cardiology, 119, 1694-1700. https://doi.org/10.1016/j.amjcard.2017.02.003

[11] Khemiri, K., Jenayah, A.A., Boudaya, F., Hamdi, A., Meskhi, S., Sfar, E., et al. (2015) Epidemiological Profile of Cardiac Pregnant Women at Tunis Maternity Center: A Service Experience. The Pan African Medical Journal, 21, Article No. 140. https://doi.org/10.11604/pamj.2015.21.140.5915 
[12] Cameroon Mother's Mean Age at First Birth-Demographics [Internet]. https://www.indexmundi.com/cameroon/mother s mean age at first birth.html

[13] Gelson, E. and Johnson, M. (2010) Effect of Maternal Heart Disease on Pregnancy Outcomes. Expert Review of Obstetrics \& Gynecology, 5, 605-617.

https://doi.org/10.1586/eog.10.49

[14] European Society of Gynecology (ESG), Association for European Paediatric Cardiology (AEPC), German Society for Gender Medicine (DGesGM), Regitz-Zagrosek, V., Blomstrom Lundqvist, C., Borghi, C., et al. (2011) ESC Guidelines on the Management of Cardiovascular Diseases during Pregnancy: The Task Force on the Management of Cardiovascular Diseases during Pregnancy of the European Society of Cardiology (ESC). European Heart Journal, 32, 3147-3197.

https://doi.org/10.1093/eurheartj/ehr218

[15] Abdel-Hady, E.-S., El-Shamy, M., El-Rifai, A.-A., Goda, H., Abdel-Samad, A. and Moussa, S. (2005) Maternal and Perinatal Outcome of Pregnancies Complicated by Cardiac Disease. International Journal of Gynecology \& Obstetrics, 90, 21-25. https://doi.org/10.1016/j.ijgo.2005.03.008

[16] PTF on Pregnancy (2019) ACOG Practice Bulletin No. 212: Pregnancy and Heart Disease. Obstetrics \& Gynecology, 133, e320.

https://doi.org/10.1097/AOG.0000000000003243

[17] Cauldwell, M., Cox, M., Gatzoulis, M., Nelson-Piercy, C., O’Brien, P., Roos-Hesselink, J.W., et al. (2017) The Management of Labour in Women with Cardiac Disease: Need for More Evidence? BJOG: An International Journal of Obstetrics \& Gynaecology, 124, 1307-1309. https://doi.org/10.1111/1471-0528.14547

[18] Bonnet, V., Simonet, T., Labombarda, F., Dolley, P., Milliez, P., Dreyfus, M., et al. (2018) Neonatal and Maternal Outcomes of Pregnancy with Maternal Cardiac Disease (the NORMANDY Study): Years 2000-2014. Anaesthesia Critical Care \& Pain Medicine, 37, 61-65. https://doi.org/10.1016/j.accpm.2017.01.005

[19] Hameed, A., Karaalp, I.S., Tummala, P.P., Wani, O.R., Canetti, M., Akhter, M.W., et al. (2001) The Effect of Valvular Heart Disease on Maternal and Fetal Outcome of Pregnancy. Journal of the American College of Cardiology, 37, 893-899. https://doi.org/10.1016/S0735-1097(00)01198-0

[20] Almange, C. (2002) Pregnancy and Congenital Heart Disease. Archives des Maladies du Coeur et des Vaisseaux, 95, 1040-1044.

[21] Drenthen, W., Pieper, P.G., Roos-Hesselink, J.W., van Lottum, W.A., Voors, A.A., Mulder, B.J.M., et al. (2007) Outcome of Pregnancy in Women with Congenital Heart Disease: A Literature Review. Journal of the American College of Cardiology, 49, 2303-2311. https://doi.org/10.1016/j.jacc.2007.03.027

[22] Siu, S.C., Colman, J.M., Sorensen, S., Smallhorn, J.F., Farine, D., Amankwah, K.S., et al. (2002) Adverse Neonatal and Cardiac Outcomes Are More Common in Pregnant Women with Cardiac Disease. Circulation, 105, 2179-2184. https://doi.org/10.1161/01.CIR.0000015699.48605.08

[23] Kologo, K., Millogo, G., Kinda, G., Adoko, H., Kambiré, Y., Thiam/Tall, A., Yaméogo, R., Samadoulougou, A. and Zabsonré, P. (2016) Valvular Heart Diseases and Pregnancy in Delivery Room at University Hospital Yalgado Ouedraogo. Open Access Library Journal, 3, 1-6. https://doi.org/10.4236/oalib.1103201 